\title{
Differential compartmentation of ornithine decarboxylase in cells of Mucor rouxii
}

\author{
Mauro Martinez-Pacheco ${ }^{1}$ and José Ruiz-Herrera ${ }^{2 *}$ \\ ${ }^{1}$ Instituto de Investigación en Biología Experimental, Universidad de Guanajuato, and ${ }^{2}$ Departamento de Genética y \\ Biología Molecular and Departamento de Ingeniería Genética, Centro de Investigación y de Estudios Avanzados del \\ Instituto Politécnico Nacional, Unidad Irapuato, Apartado Postal 629, Irapuato, Gto., Mexico
}

(Received 30 November 1992; revised 22 January 1993; accepted 28 January 1993)

\begin{abstract}
A study was made to obtain an explanation for the differential effect in Mucorales of the ornithine decarboxylase (ODC) inhibitors 1,4-diamino-2-butanone (DAB) and $\alpha$-difluoromethylornithine (DFMO), only the first of which affects cell differentiation; and for the paradoxical result that while it inhibits this process, DAB has no further effect on cell growth. Results obtained with cells permeabilized by two different methods which respectively do or do not affect internal membranes, and with protoplasts lysed under iso-osmotic conditions, suggest that the plasmalemma from $M$. rouxii cells is permeable to DAB, but not to DFMO, and that ODC is present in more than one cell compartment. ODC from the distinct cell compartments was differentially accessible to its substrate, and to DAB or DFMO, providing a reasonable explanation for the above results.
\end{abstract}

\section{Introduction}

The importance of polyamines in cell differentiation of Mucor species has been amply demonstrated. Inderlied $e t$ al (1980) demonstrated that during the yeast-to-mycelium transition of Mucor racemosus there occurred a significant increase in the levels of ornithine decarboxylase (ODC) activity. ODC is a key enzyme in the regulation of polyamine biosynthesis (Tabor \& Tabor, $1984,1985)$ and the only source of putrescine in most fungi (Stevens \& Winther, 1979; Tabor \& Tabor, 1985). A similar rise in ODC, as well as an increase in the levels of polyamines occurs during the dimorphic transition and spore germination of Mucor rouxii (CalvoMendez et al., 1987; Martinez-Pacheco et al., 1989). Yeast monomorphic mutants of Mucor bacilliformis were found to contain ODC levels between 6 and 52 times lower than wild-type cells (Ruiz-Herrera et al., 1983).

Particularly relevant in these studies was the observation that 1,4-diamino-2-butanone (DAB), a com-

\footnotetext{
* Author for correspondence: (mail should be addressed to the Departamento de Ingeniería Genética). Tel. 52462 51600; fax 52462 51282.
}

Abbreviations: DAB, 1,4-diamino-2-butanone; DFMO, $\alpha$-difluoromethylornithine; ODC, ornithine decarboxylase. petitive inhibitor of ODC (Stevens et al., 1977), inhibited the germination of species from different Mucorales specifically at the step of germ-tube emergence (RuizHerrera \& Calvo-Mendez, 1987; Obregon et al., 1990), and the yeast-to-mycelial transition of $M$. rouxii (Martinez-Pacheco et al., 1989). Moreover, the effect of DAB clearly separated growth from differentiation. If added before a critical period DAB stopped cell differentiation but after that period its addition had no effect on the process, and did not inhibit cell growth (Ruiz-Herrera \& Calvo-Mendez, 1987; MartinezPacheco et al., 1989). These results give rise to a paradox, since polyamines are growth factors and mutants affected in their synthesis are auxotrophic (Winther \& Stevens, 1978; Tabor et al., 1982; Tabor \& Tabor, 1985). Three possible alternatives can be envisaged to explain this discrepancy: (1) cells become permeable to DAB only at certain critical periods; (2) there is more than one pool of ODC and polyamines, one of which is resistant to the drug (the role played by polyamine compartmentation in their accessibility for trophic reactions has been emphasized by Davis et al., 1992); (3) there is more than one form of ODC in the cell. This last possibility seems unlikely since in those fungal systems for which cloning has been performed, a single gene has been detected (Fonzi \& Sypherd, 1987; Williams et al., 1992).

In order to gain information on this problem, the present study was undertaken. The results obtained 
suggest the presence of ODC in several cell compartments. Sensitivity of the enzyme to the inhibitors depends on its accessibility, explaining the previous observations.

\section{Methods}

Strain and growth conditions. M. rouxii IM80 (ATCC 24905) was used in this study. It was maintained on slants of solid YPG medium (Bartnicki-Garcia \& Nickerson, 1962). Large numbers of spores were obtained from Roux bottles containing solid YPG medium. After $4 \mathrm{~d}$ growth at $28^{\circ} \mathrm{C}$, spores were harvested with sterile distilled water, washed three times with sterile distilled water by centrifugation, resuspended in sterile distilled water and kept at $4{ }^{\circ} \mathrm{C}$ for not more than $5 \mathrm{~d}$. Spores were inoculated into liquid YPG medium at a final density of $5 \times 10^{5}$ spores $\mathrm{ml}^{-1}$ and incubated at $28^{\circ} \mathrm{C}$ in a water bath shaken at 120 r.p.m. for variable periods of time.

Cell permeabilization. (a) Toluene/ethanol. Spores inoculated into YPG medium were incubated for $4.6 \mathrm{~h}$ until they had produced a germ tube of about 1.5-2 times the size of the spore. These cells (germlings) were recovered by filtration through Millipore filters $(0.45 \mu \mathrm{m}$ pore diameter), washed with $20 \mathrm{~mm}$-potassium phosphate buffer containing $10 \mathrm{~mm}$-EDTA and treated with a $0 \cdot 1$ volume of a mixture of toluene/ethanol $(1: 4, \mathrm{v} / \mathrm{v})$ as described by Basabe et al. (1979). Germlings were washed seven times with buffer by centrifugation to remove the solvents and finally resuspended in $0.1 \mathrm{M}$-potassium phosphate buffer $\mathrm{pH} 7 \cdot 3$ containing $1 \mathrm{~mm}$-EDTA, 2 mM-dithiothreitol and $0.2 \mathrm{mM}$-pyridoxal phosphate (PEDP buffer).

(b) DEAE-dextran. Cells were washed as above and then with $10 \mathrm{~mm}$ Tris/ $\mathrm{HCl}$ buffer $\mathrm{pH} 7.3$ containing $0.7 \mathrm{M}$-sorbitol (TTS). They were then treated with DEAE-dextran as described by Huber-Walchli \& Wiemken (1979). In some experiments, cells permeabilized by this method were later treated with toluene/ethanol as described above. The efficiency of either method was assessed by staining with $10 \mu \mathrm{g}$ berberine sulphate $\mathrm{ml}^{-1}$ for $3 \mathrm{~min}$, followed by microscopic observation under phase contrast and fluorescence. Berberine is a fluorescent probe which does not penetrate into intact cells. At least 300 cells were scored in these experiments.

Preparation of cell-free extracts by ballistic disruption. Cells were harvested as above, resuspended in $20 \mathrm{ml}$ PEDP buffer in a Duran flask, mixed with $20 \mathrm{ml}$ glass beads $(0.45 \mathrm{~mm}$ diameter $)$ and broken in a Braun MSK cell homogenizer for 1 min while cooling with a stream of $\mathrm{CO}_{2}$. Extracts were centrifuged as indicated in the corresponding experiments.

Preparation of protoplasts and metabolic lysis. Cells were treated with a lytic complex from Streptomyces sp. as described by Ramirez-Leon \& Ruiz-Herrera (1972) in $0.1 \mathrm{M}$-phosphate buffer containing $0.7 \mathrm{M}$ sorbitol. Absence of a cell wall was determined by staining with Calcofluor and by their sensitivity to osmotic shock. Normally, full conversion to protoplasts took place in $60-90 \mathrm{~min}$ at $37^{\circ} \mathrm{C}$. Protoplasts were centrifuged at $1000 \mathrm{~g}$ in a swinging bucket rotor over a cushion of a solution of $0.6 \mathrm{M}$-sucrose, $1.5 \%(\mathrm{w} / \mathrm{v})$ Ficoll, and $0.7 \mathrm{M}$-sorbitol in 10 mM-phosphate buffer $\mathrm{pH}$ 6.0. Protoplasts were recovered and filtered through a siliconized glass-wool column which eliminated whole cells and cell debris. Protoplasts were lysed by a method similar to that described by Schwencke et al. (1983). Protoplasts were treated with $10 \mathrm{pg}$ DEAE-dextran per protoplast for $1 \mathrm{~min}$. The reaction was stopped by addition of $10 \mathrm{pg}$ dextran sulphate per protoplast, and the suspension was centrifuged at $1000 \mathrm{~g}$ for $5 \mathrm{~min}$ in a swinging bucket rotor. Protoplasts were washed by centrifugation with hypertonic buffer, resuspended in the same buffer and incubated with $5 \mathrm{~mm}$ - glucose at $30{ }^{\circ} \mathrm{C}$. In $15-30 \mathrm{~min} 95 \%$ of the total number of protoplasts had been lysed as assessed by microscopic observation.

Determination of enzymic activities. Ornithine decarboxylase was measured by the liberation of radioactive ${ }^{14} \mathrm{CO}_{2}$ as modified by CalvoMendez et al. (1987) from the method of Sissions (1976). Activity was expressed as nmol $\mathrm{CO}_{2}$ liberated $\mathrm{min}^{-1}$. Specific activity was related to $1 \mathrm{mg}$ protein. Chitin synthetase activity was measured by the filtration method originally described by Ruiz-Herrera \& Bartnicki-Garcia (1976).

Determination of polyamines. Polyamines were measured by the modification described by Calvo-Mendez et al. (1987) to the techniques of Garcia et al. (1980) and Seiler (1983). Concentration was expressed as nmol putrescine or spermidine (mg cell protein) ${ }^{-1}$.

Electron microscopy. Cells were fixed with $2 \%(\mathrm{v} / \mathrm{v})$ glutaraldehyde in $0 \cdot 1 \mathrm{M}$-cacodylate buffer $\mathrm{pH} 7 \cdot 0$, and postfixed with $2 \%(\mathrm{w} / \mathrm{v})$ osmium tetroxide. Samples were dehydrated in a graded acetone series and embedded in Epon-Araldite. Silver interference colour sections were collected on copper grids coated with Formvar and carbon, and post-stained with lead citrate. Sections were examined and photographed with a Jeol $100 \mathrm{~S}$ transmission electron microscope, operating at $80 \mathrm{kv}$.

Miscellaneous. Respiration was measured with a Clark oxygen electrode (Silver Spring). Molecular filtration of ODC from a $100000 \mathrm{~g}$ supernatant of cell-free extracts was performed on a Bio-Gel P100 (Bio-Rad) column $(1.6 \times 39.5 \mathrm{~cm})$, washed and eluted with PEPD buffer. Fractions ( $1 \mathrm{ml}$ ) were collected and $A_{280}$ and ODC activity were measured. Protein was measured by the Lowry method after solubilization with $1 \mathrm{M}-\mathrm{NaOH}$. Bovine serum albumin was used as standard. All experiments were performed with duplicate samples and were repeated at least twice.

\section{Results and Discussion}

As described previously (Ruiz-Herrera \& Calvo-Mendez, 1987), both DAB and DFMO are efficient inhibitors of $M$. rouxii ODC when tested in vitro. Nevertheless their effect in vivo is completely different; whereas DAB inhibits spore germination at the step of germ tube formation, DFMO has no effect whatsoever on the process. We hypothesized at that time that the cells might be permeable to DAB but not to DFMO. A second possibility would be that the effect of DAB was in fact unrelated to polyamine metabolism. In order to distinguish between these alternatives we measured the effect of both drugs on the levels of polyamines in the fungus. Spores were inoculated into YPG medium in the presence or absence of DAB, DFMO, or a mixture of both inhibitors. At intervals, samples were removed, cells harvested, and the polyamine concentration measured as described in Methods. The results obtained (Fig. 1) demonstrated that DAB, but not DFMO, depressed the levels of polyamines. The mixture of the drugs was not synergic, and the same degree of inhibition was observed when either DAB alone or DAB plus DFMO were added to the cultures. These results demonstrate that the DAB effect is indeed specific in blocking polyamine biosynthesis, and that the ineffectiveness of DFMO is 


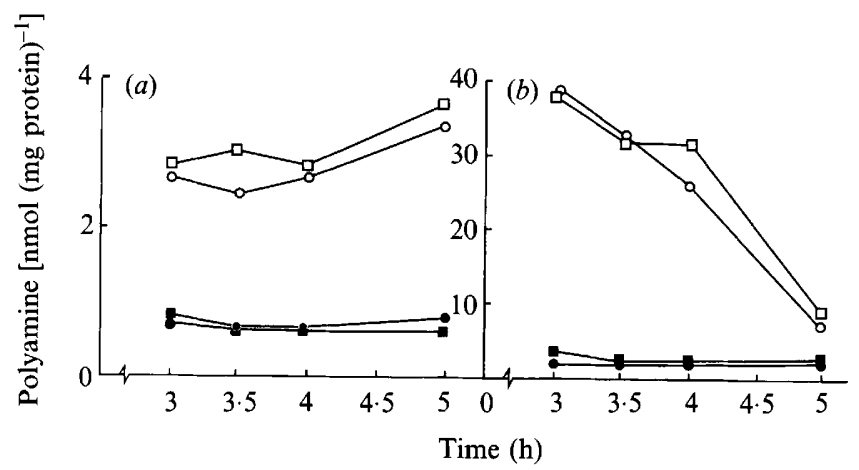

Fig. 1

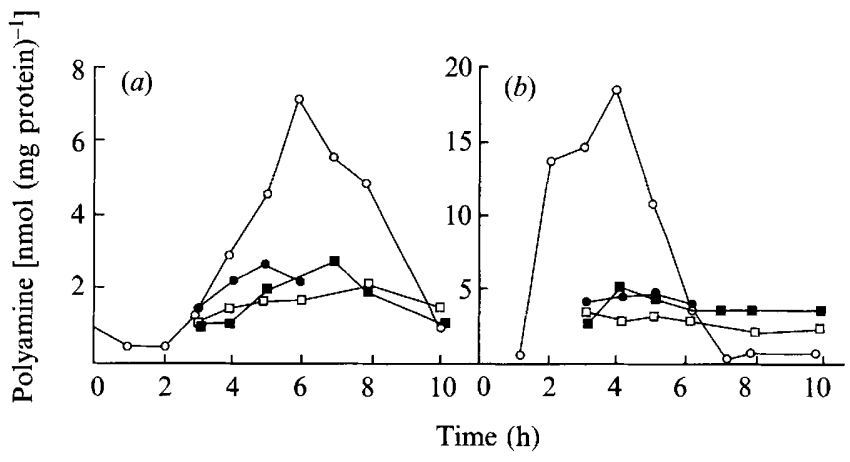

Fig. 2

Fig. 1. Effect of DAB and DFMO on polyamine levels of germinating spores of $M$. rouxii. Spores were inoculated into liquid YPG medium in the presence or absence of $1 \mathrm{~mm}-\mathrm{DAB}$ and/or DFMO. At intervals samples were removed, cells were harvested by centrifugation, and polyamines were measured. (a) Putrescine; (b) spermidine. Control (O); DAB only (O); DFMO only ( $\square$ ); DAB plus DFMO ( $\mathbf{\square})$. Average values of two different experiments.

Fig. 2. Effect of different DAB concentrations on polyamine levels of germinating spores of $M$. rouxii. The same protocol described for Fig. 1 was used, but the following DAB concentrations were used: none (control) (O); 0.1 $\mathrm{mm}(\mathbf{O}) ; 1 \mathrm{mM}(\square) ; 10 \mathrm{~mm}(\boldsymbol{\square})$. Average values of two different experiments.

probably related to its impermeability at the level of plasmalemma. This latter conclusion received further support when the effect on permeabilized cells was tested (see Table 2). One unexpected result was that the levels of both putrescine and spermidine were never completely depressed by the drug. The possibility was entertained therefore that the amount of DAB added to the cells was not enough to block ODC activity completely in vivo, perhaps also owing to permeability problems. This was not so. The same degree of inhibition of the polyamine levels in the cells was brought about when cultures were supplemented with either $0 \cdot 1 \mathrm{mM}, 1 \mathrm{~mm}$ or $10 \mathrm{~mm}$-DAB; i.e. a 100 -fold increase in the drug concentration was unable to overcome the residual levels of putrescine and spermidine (Fig. 2).

These results may have two likely explanations; there is a form of ODC resistant to DAB, or the enzyme is present in more than one compartment of the cell, one of which is impermeable to the drug. The first of these is unlikely since, confirming previous results (Ruiz-Herrera \& Calvo-Mendez, 1988), we found that either $1 \mathrm{mm-DAB}$ or DFMO completely inhibit ODC activity in toluenepermeabilized cells (see Table 2).

Further experiments were devised to test the second alternative. We measured ODC activity in situ under conditions which preserved the integrity of cell organelles. DEAE-dextran of a high molecular mass (about $500 \mathrm{kDa}$ ) has been used to permeabilize cells and to study the pool size of different metabolites such as inorganic ions or ATP (Huber-Walchli \& Wiemken, 1979; Eilam et al., 1985). The polycation disorganizes the plasmalemma, but its large size prevents its penetration into the cell, and therefore it does not affect internal

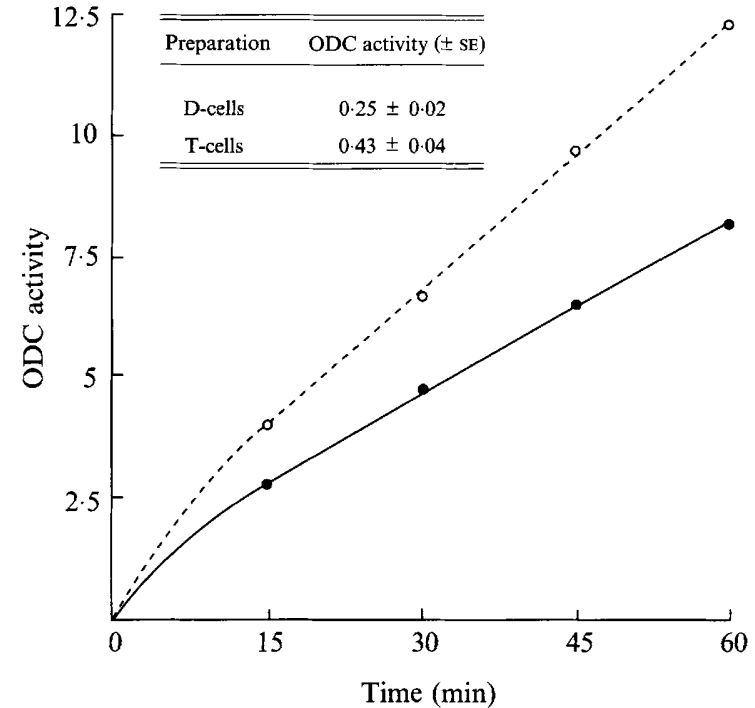

Fig. 3. Ornithine decarboxylase activity in permeabilized germlings of $M$. rouxii. Germlings (5-h-old) were harvested, and permeabilized with either DEAE-dextran only (D-cells) (O), or with DEAE-dextran followed by toluene/ethanol (T-cells) $(O)$. ODC activity was measured at the indicated times of incubation. Activity is expressed as $\mathrm{nmol} \mathrm{CO}_{2}$ (mg protein) ${ }^{-1}$. Average values of two different experiments. Inset: table showing ODC activity of D- and T-cells measured in twelve different experiments ( $60 \mathrm{~min}$ incubation). Activity is expressed as nmol $\mathrm{CO}_{2}$ liberated $\mathrm{min}^{-1}(\mathrm{mg} \text { cell protein })^{-1}$.

membranes. When ODC activity of germlings permeabilized with DEAE-dextran (D-cells) was compared to that from cells sequentially permeabilized with DEAEdextran and then with toluene/ethanol (T-cells), lower levels were observed: $57 \pm 6 \%$ compared to T-cells in twelve independent experiments (Fig. 3). The difference was attributed to the existence of more than one pool of 

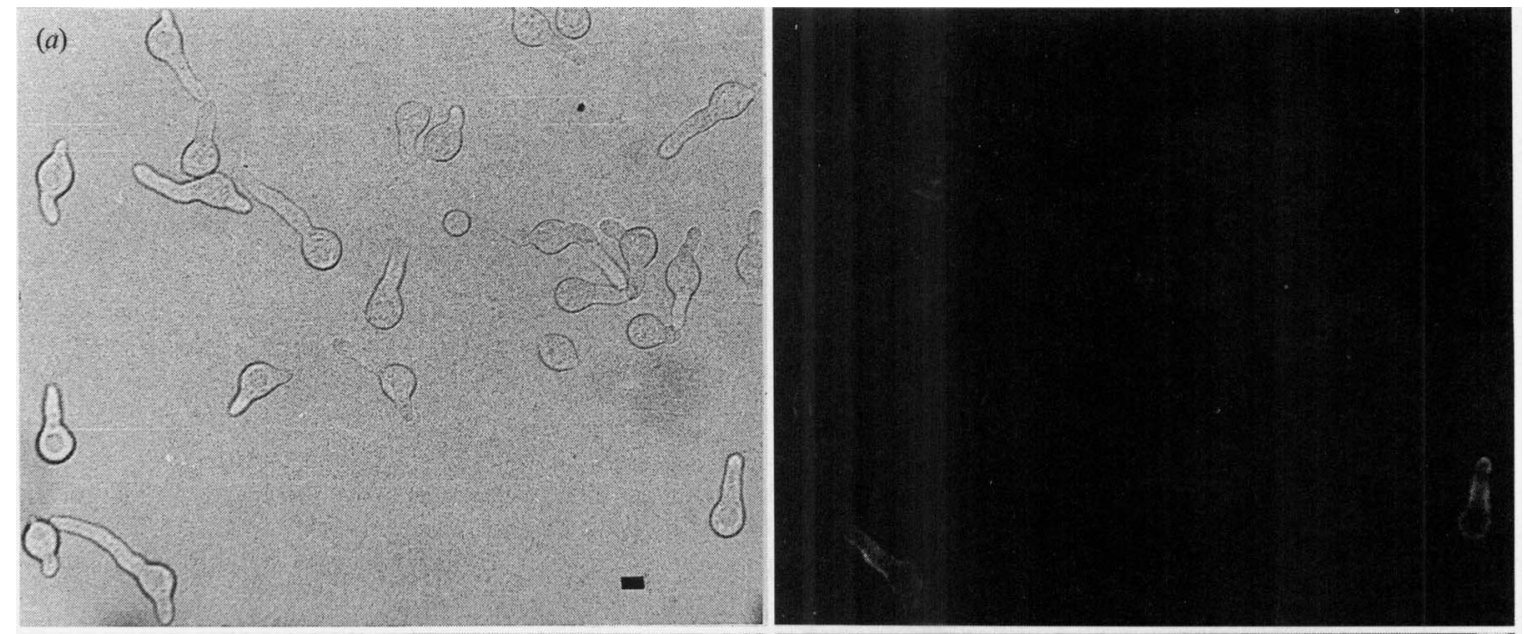

(b)

o
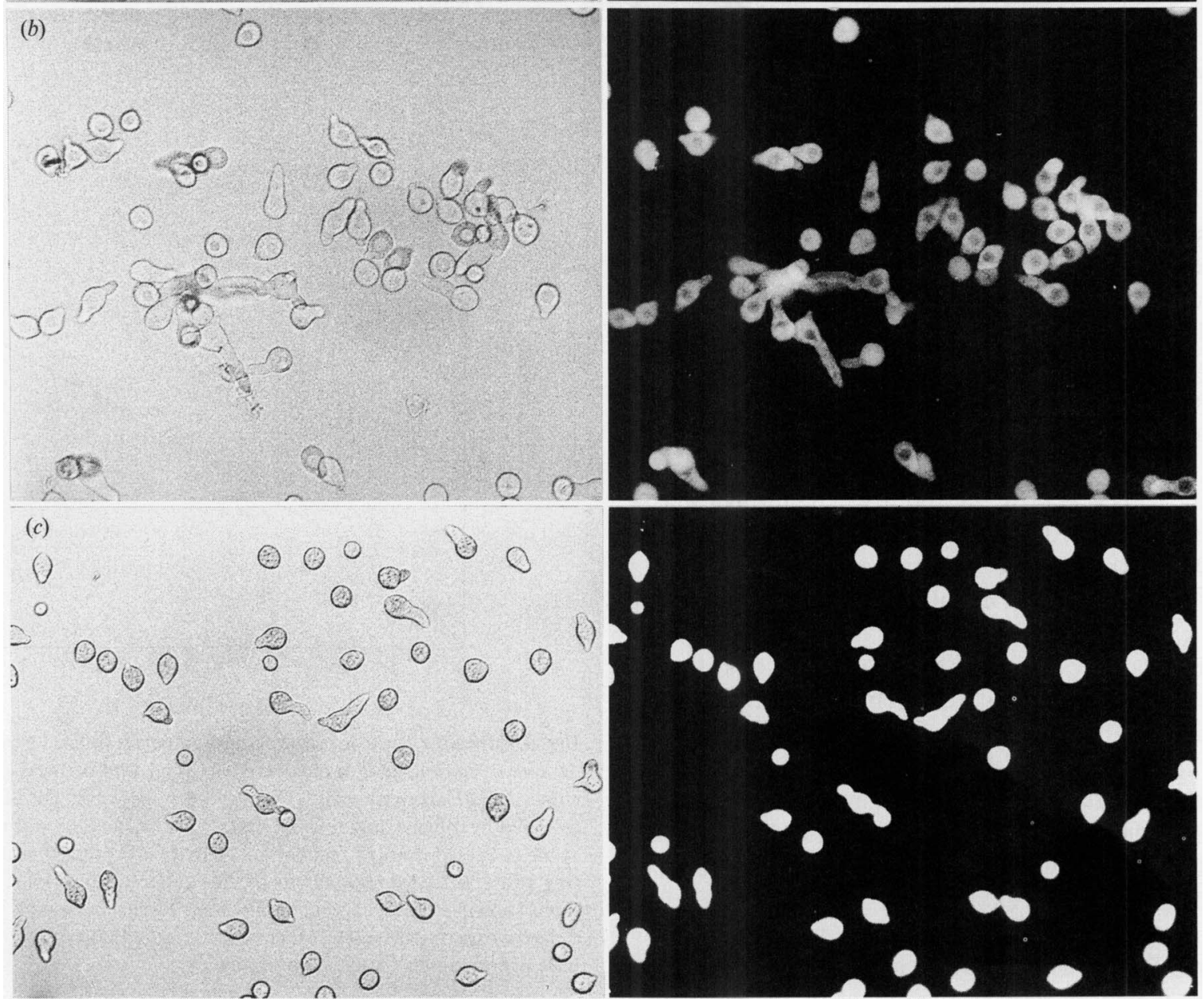

Fig. 4. Appearence of intact and permeabilized germlings stained with berberine sulphate. Bright field (left); fluorescent microscopy (right). (a) Intact germlings; (b) T-cells; (c) D-cells. All photographs taken at the same magnification. Bar marker in $(a), 10 \mu \mathrm{m}$.

the enzyme, one of which was inaccessible to external substrate.

The following are alternative possible explanations:
(1) differences in the yield of permeabilized cells by either method; (2) alterations of intracellular membranes; and (3) stimulatory effect of toluene on ODC. All of these 

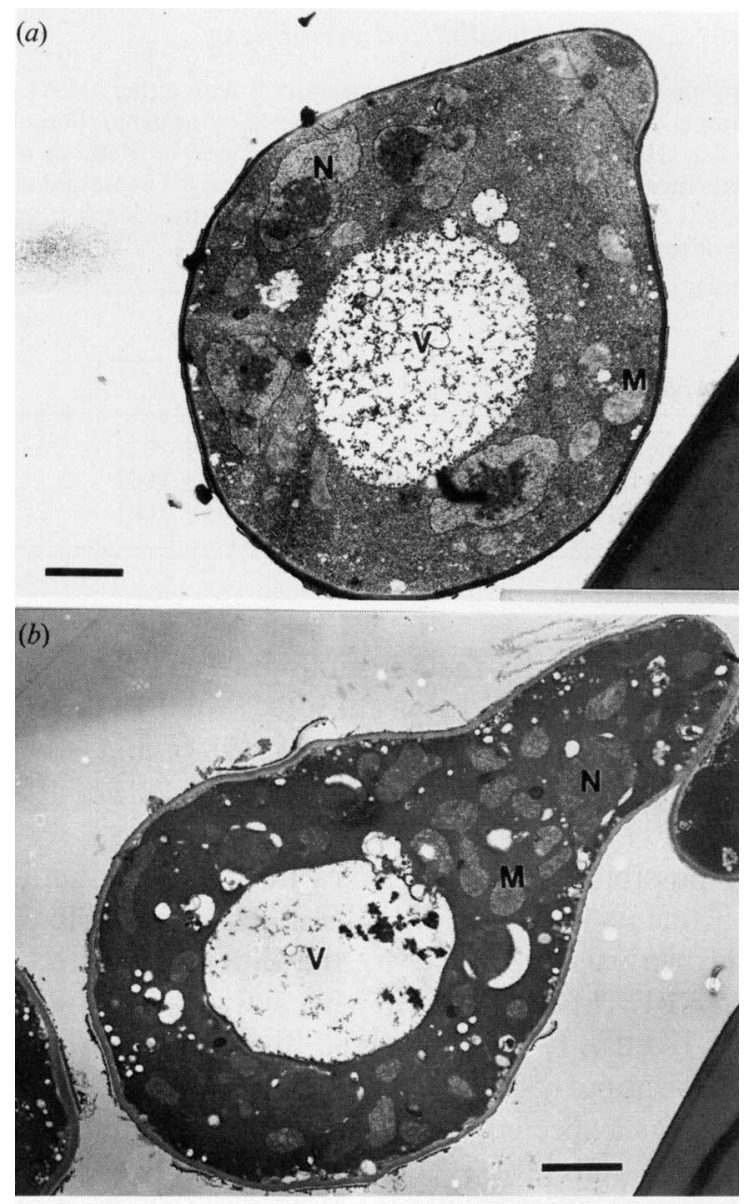

(c)

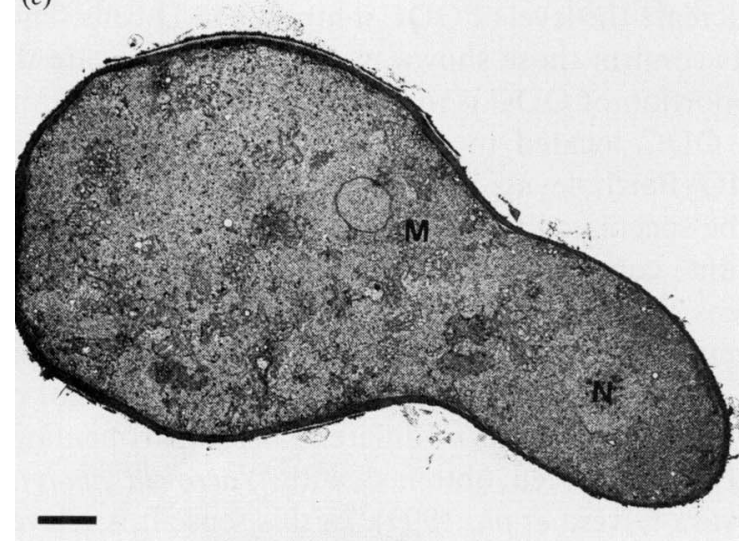

Fig. 5. Electron microscopic structure of normal and permeabilized germlings of $M$. rouxii. (a) Native cells; (b) D-cells; (c) T-cells. V, vacuoles; $\mathrm{M}$, mitochondria; $\mathrm{N}$, nuclei. Bar markers, $2 \mu \mathrm{m}$.

were ruled out. Firstly, yields of permeabilized cells by either procedure were measured using as a criterion the penetration of the normally non-permeable fluorescent probe, berberine sulphate. In a number of experiments it was demonstrated that more than $95 \%$ of the cells permeabilized with DEAE-dextran or toluene/ethanol took in the compound, although the appearance of the cells was different. D-cells showed a dark central body (the vacuole, which is impermeable to berberine) which was absent in T-cells (Fig. 4). Further experiments to confirm that $\mathrm{D}$ - and $\mathrm{T}$-cells were equally permeable to otherwise non-penetrating compounds, made use of the determination of chitin synthetase activity. $M$. rouxii germlings are impermeable to UDP-GlcNAc and do not incorporate GlcNAc into chitin upon addition of external substrate. On the other hand, cells permeabilized with toluene incorporate GlcNAc from exogenous UDPGlcNAc into chitin, i.e. they are permeable to the substrate (Sentandreu \& Ruiz-Herrera, 1978). It was observed that chitin synthetase activity dependent on external radioactive UDP-GlcNAc displayed by D- and T-cells was the same (not shown).

Electron microscopic observation of D-cells revealed that the membranes of nuclei, mitochondria and the vacuole were preserved, in contrast to T-cells where they practically disappeared (Fig. 5). Integrity of mitochondria in permeabilized cells was assessed by their respiratory capacity using NADH as external substrate. D-cells, in contrast to T-cells, oxidized externallysupplied NADH (NADH does not penetrate into intact germlings). This respiratory activity was resistant to rotenone. It is known that the mitochondria of Saccharomyces cerevisiae (Van Jagow \& Klingenberg, 1970) and Candida albicans (Light \& Garland, 1971) possess an NADH dehydrogenase oriented towards the cytosol.

The effect of a mixture of toluene/ethanol on ODC activity was measured in crude cell-free extracts prepared with a Braun homogenizer. Toluene was removed by centrifugation over a sucrose cushion. No stimulation or inhibition, nor a change in the distribution of the enzyme compared to control extracts were observed. In each case almost all ODC activity appeared in the supernatant (Table 1). The mobility behaviour of ODC in a Bio-Gel P100 column was also unaffected by toluene treatment. When high-speed supernatants obtained from either extract were filtered through a gel column, a single symmetrical peak of activity was eluted at the same position (not shown). These latter experiments were performed to determine whether activation of the enzyme in situ by toluene was related to its removal from a membrane (see Mustelin et al., 1987), or else to the liberation of high molecular-mass inhibitors or antienzymes described in other systems (McCann, 1980; Tabor \& Tabor, 1984; Canellakis et al., 1985).

Additional experiments provided evidence that the effect of toluene was not a specific one, but that it merely made accessible a pool of ODC to external substrate. Osmotic shock of D-cells was as effective as toluene/ethanol in increasing the levels of ODC activity. 


\section{Table 1. Subcellular distribution of $O D C$}

(a) Whole germlings were disrupted in a Braun cell homogenizer and the extract was centrifuged at $105000 \mathrm{~g}$ for $45 \mathrm{~min}$. Aliquots of supernatant (S4) or resuspended pellet (P4) were treated for $10 \mathrm{~min}$ with toluene/ethanol, and centrifuged as above over a cushion of $0.6 \mathrm{M}$-sucrose. ODC activity of supernatant and sediment was measured. (b) Protoplasts were lysed under hypertonic conditions as described in Methods. Extracts were sequentially centrifuged at $500 \mathrm{~g}(5 \mathrm{~min}), 2300 \mathrm{~g}(5 \mathrm{~min}), 11500 \mathrm{~g}$ $(10 \mathrm{~min})$, and $105000 \mathrm{~g}(45 \mathrm{~min})$. The resulting pellets (P1-P4 respectively), and the final supernatant (S4) were recovered. ODC activity of each fraction was measured. Results are averages of two experiments.

\begin{tabular}{lccc}
\hline \hline & \multicolumn{3}{c}{ Relative ODC activity (\%) } \\
\cline { 2 - 3 } & \multicolumn{2}{c}{ (a) Ballistic disruption } \\
\cline { 2 - 3 } Fraction & Control & + Toluene & $($ b $)$ Osmotic lysis \\
\hline P1 & - & - & 21 \\
P2 & - & - & 6 \\
P3 & - & - & 2 \\
P4 & $<1$ & $<1$ & 67 \\
S4 & $>99$ & $>99$ & 3 \\
\hline \hline
\end{tabular}

Thus whereas DEAE-dextran-treated cells had an ODC specific value of 0.069 , toluene-treated or osmoticallyshocked cells displayed values of 0.110 and 0.107 respectively. Osmotically shocked cells lost their vacuoles as judged by their microscopic appearance when stained with berberine sulphate.

Protoplasts were prepared from germlings and metabolically lysed under iso-osmotic conditions as described in Methods. Total breakage was obtained. Extracts were differentially centrifuged at $500 \mathrm{~g}, 2300 \mathrm{~g}$, $11500 \mathrm{~g}$ and $105000 \mathrm{~g}$, and ODC activity in each pellet and in the final high speed supernatant was measured. It was observed that almost all ODC activity appeared associated with particulate fractions in contrast to the results obtained in cell-free extracts prepared by ballistic disruption (Table 1). Taking into consideration that ODC is a relatively low-molecular-mass, soluble enzyme, this and the above results suggest that the enzyme is present in osmotically sensitive membranous organelles. Such organelles are susceptible to breakage during ballistic cell disruption liberating the soluble ODC. By microscopic observation, DNA measurement with diphenylamine and determination of respiratory activity with an oxygen electrode, we concluded that $\mathbf{P} 1, \mathbf{P} 2$, and P3 (Table 1) were respectively enriched in vacuoles, nuclei and mitochondria; P4 is probably enriched in endoplasmic reticulum (ER).

In other systems, ODC distribution in two cell compartments has been demonstrated. In germinating barley seeds (Panogiotidis et al., 1982) and Physarum polycephalum (Kuehn et al., 1983) ODC activity has been detected in both nuclei and cytosol. A similar distribution

\section{Table 2. Effect of $D A B$ and $D F M O$ on $O D C$ activity of} permeabilized germlings

Germlings grown for $5 \mathrm{~h}$ were permeabilized with either DEAEdextran (D-cells), or DEAE-dextran followed by toluene/ethanol (T-cells). ODC activity was measured as described in Methods in the presence or absence of inhibitors. ODC activity is expressed as $\mathrm{nmol} \mathrm{CO}_{2} \min ^{-1}$ (mg cell protein $)^{-1}$. Values are the means from three different experiments $\pm \mathrm{SE}$.

\begin{tabular}{lcc}
\hline \hline & \multicolumn{2}{c}{ ODC specific activity } \\
\cline { 2 - 3 } Addition & D-cells & T-cells \\
\hline None & $0 \cdot 114 \pm 0 \cdot 01$ & $0 \cdot 225 \pm 0 \cdot 02$ \\
1 mM-DAB & $0 \cdot 051 \pm 0 \cdot 004$ & $0 \cdot 008 \pm 0 \cdot 001$ \\
1 mM-DFMO & $0 \cdot 063 \pm 0 \cdot 005$ & $0 \cdot 004 \pm 0 \cdot 001$ \\
\hline \hline
\end{tabular}

was demonstrated by the autoradiographic detection of the complex formed between ODC and radioactive DFMO in rat liver (Bartholeyns, 1983) and mouse kidney (Zagon et al., 1984; Panogiotidis et al., 1982; Sklaviadis et al., 1985).

The possibility that ODC present in the distinct cell compartments in $M$. rouxii had a different physiological significance was suggested by the differential effect of DAB and DFMO on the enzymic activity displayed by D- or T-cells. It was observed that either inhibitor produced about $50 \%$ inhibition of ODC in D-cells whereas, as expected, they blocked completely ODC activity in T-cells (Table 2). Use of higher concentrations of either drug up to $10 \mathrm{~mm}$ or combinations of both, did not increase the level of ODC inhibition in D-cells. These results confirm those shown in Fig. 1, and indicate that a proportion of ODC is inaccessible to the drugs. In rat liver, ODC located in cell nuclei is not accessible to DFMO (Bartholeyns, 1983). According to these results it may be speculated that the enzyme present in the drugresistant compartment(s) is related to cell growth, whereas the sensitive one(s) would be involved in cell differentiation. This hypothesis would explain the paradox that DAB inhibits cell differentiation, but not cell growth. Similar results of differential compartmentation of ODC have been obtained with Yarrowia lipolytica (Guevara-Olvera et al., 1993). In this sense it is relevant that the behaviour of ODC present in different compartments may vary in some organisms. Thus, whereas rat liver cytoplasmic activity is increased by partial hepatectomy or dexamethasone, nuclear activity is not (Bartholeyns, 1983). Levels of cytoplasmic and nuclear ODC activities in $T$. pyriformis change at a different rate during the growth periods (Sklaviadis et al., 1985). Regarding ODC inaccessible to internal ornithine, it may be within a compartment where its own substrate is synthesized, or else it may be an inactive pool which is transported to a different ornithine-permeable com- 


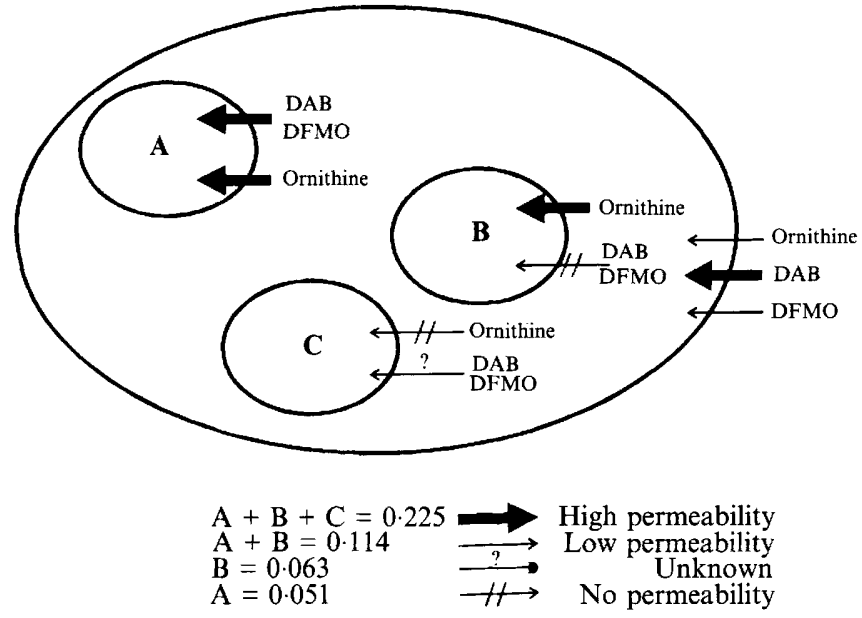

Fig. 6. Schematic representaqtion of the hypothetical subcellular distribution of ODC in $M$. rouxii. Three different pools recognized by their different permeability to substrate and inhibitors are represented. Data to illustrate their approximate ratios were taken from Table 2.

partment at critical periods of growth or development. Fig. 6 shows a hypothetical representation of the data regarding the existence of more than one ODC pool in M. rouxii.

This work was partially supported by the Consejo Nacional de Ciencia y Tecnología (CONACyT) and Grant C11*.0631 from the Commission of European Communities. M.M.P. was a pre-doctoral fellow from CONACyT. J.R.H. is a National Investigador, México. We thank Dr P. P. McCann from the Merrell-Dow Research Institute for his generous gift of a sample of DFMO, and Mr Armando Obregon for his technical assistance in EM work. Thanks are given to Mrs Carmen Medrano for careful typing of the manuscript.

\section{References}

BARTHOLEYNS, J. (1983). Subcellular distribution of ornithine decarboxylase in rat liver and accessibility of the enzyme to difluoromethylornithine, and irreversible inhibitors of ornithine decarboxylase. Life Sciences 32, 1305-1312.

BARTNICKI-GARCIA, S. \& Nickerson, W. J. (1962). Induction of yeastlike development in Mucor by carbon dioxide. Journal of Bacteriology 84, 829-840.

Basabe, J. R., Catherine, A. L. \& Weiss, R. L. (1979). Enzyme assays using permeabilized cells of Neurospora crassa. Analytical Biochemistry 92, 356-360.

Calvo-Mendez, C., Martinez-Pacheco, M. \& Ruiz-Herrera, J. (1987). Regulation of ornithine decarboxylase activity in Mucor bacilliformis and Mucor rouxii. Experimental Mycology 11, 270-277.

Canellakis, E. S., Kyriakidis, O. A., Reinhart, S., Huang, C., PANAGIOTIDIs, C. \& Fong, W. F. (1985). Regulation of polyamine biosynthesis by antizyme and some recent development relating the induction of polyamine biosynthesis to cell growth. Bioscience Reports 5, 189-204.

Davis, R.H., Morris, D. R. \& Coffino, P. (1992). Sequestered end products and enzyme regulation. The case of ornithine decarboxylase. Microbiological Reviews 56, 280-290.

Eilam, Y., Lavi, H. \& Grossowicz, N. (1985). Cytoplasmic $\mathrm{Ca}^{2+}$ homeostasis maintained by a vacuolar $\mathrm{Ca}^{2+}$ transport system in the yeast Saccharomyces cerevisiae. Journal of General Microbiology 131, 623-629.
FonZI, W. A. \& SYPHERD, D. P. (1987). The gene and the primary structure of ornithine decarboxylase from Saccharomyces cerevisiae. Journal of Biological Chemistry 262, 10127-10133.

Garcia, J. R., Hiatt, W. R., Peters, J. \& Sypherd, P. S. (1980). Sadenosylmethionine levels and protein methylation during morphogenesis of Mucor racemosus. Journal of Bacteriology 142, 196-201.

Guevara-Olvera, L., Calvo-Mendez, C. \& Ruiz-Herrera, J. (1993). The role of polyamine metabolism in dimorphism of Yarrowia lipolytica. Journal of General Microbiology 139, 485-493.

Huber-Walchli, U. \& WiemKen, A. (1979). Differential extraction of soluble pools from the cytosol and the vacuoles of yeast Candida utilis using DEAE-dextran. Archives of Microbiology 120, 141-149.

Inderlied, C. B., Cinlar, R. L. \& SyPherd, P. S. (1980). Regulation of ornithine decarboxylase during morphogenesis of Mucor racemosus. Journal of Bacteriology 141, 696-706.

Kuehn, G. D., Atmar, V. J. \& Daniels, G. R. (1983). Polyaminedependent protein kinase from the slime mould Physarum polycephalum. Methods in Enzymology 94, 147-154.

Light, P. A. \& Garland, P. B. (1971). A comparison of mitochondria from Torulopsis utilis grown on continuous culture with glycerol, iron, ammonium, magnesium or phosphate as the growth-limiting medium. Biochemical Journal 124, 123-134.

MCCANN, P. P. (1980). Regulation of ornithine decarboxylase in eukaryotes. In Polyamines in Biochemical Research, pp. 109-123. Edited by J. M. Gaugas. New York: Wiley.

Martinez-Pacheco, M., Rodriguez, G., Reyna, G., Calvo-Mendez, C. \& Ruiz-Herrera, J. (1989). Inhibition of the yeast-mycelial transition and the phorogenesis of Mucorales by diaminobutanone. Archives of Microbiology 151, 10-14.

Mustelin, T., Posso, H., Sepro, P. L., Gynther, J. \& Anderson, L. C. (1987). Growth signal transduction: rapid activation of covalently bound ornithine decarboxylase during phosphatidylinositol breakdown. Cell 49, 171-176.

Obregon, A., Monzalvo, S., Calvo-Mendez, C. \& Ruiz-Herrera, J. (1990). Ultrastructural and chemical alterations in germinating sporangiospores of Mucor rouxii (Zygomycetes), induced by two compounds which inhibit their developmental pattern. Cryptogamic Botany 1, 323-335.

Panogiotidis, C. A., Georgatsos, I. G. \& Kyriakidis, D. A. (1982). Superinduction of cytosolic and chromatin-bound ornithine decarboxylase activities of germinating barley seeds by actinomycin D. FEBS Letters 146, 193-196.

Ramirez-Leon, I. F. \& Ruiz-HerRera, J. (1972). Hydrolysis of walls and formation of sphaeroplasts in Mucor rouxii. Journal of General Microbiology 72, 281-290.

Ruiz-Herrera, J. \& Bartnicki-Garcia, S. (1976). Proteolytic activation and inactivation of chitin synthetase from Mucor rouxii. Journal of General Microbiology 97, 241-249.

Ruiz-Herrera, J. \& Calvo-Mendez, C. (1987). Effect of ornithine decarboxylase inhibitors on the germination of sporangiospores of Mucorales. Experimental Mycology 11, 287-296.

Ruiz-Herrera, J., RuIZ, A. \& Lopez-Romero, E. (1983). Isolation and biochemical analysis of Mucor bacilliformis monomorphic mutants. Journal of Bacteriology 156, 264-272.

SChWENCKe, J., CANUT, H. \& FloRes, A. (1983). Simultaneous isolation of yeast cytosol and well preserved mitochondria with negligible contamination by vacuolar proteinases. FEBS Letters 131, 296-300.

SEILER, N. (1983). Liquid chromatographic methods for assaying polyamines using prechromatographic derivatization. Methods in Enzymology 94, 10-25.

Sentandreu, R. \& Ruiz-Herrera, J. (1978). In situ study of the localization and regulation of chitin synthetase in Mucor rouxii. Current Microbiology 1, 77-80.

Sissions, C. H. (1976). Improved technique for accurate and convenient assay of biological reactions liberating $\mathrm{CO}_{2}$. Analytical Biochemistry $70,454-462$.

Sklaviadis, T. K., Georgatsos, J. G. \& Kyriakidis, D. A. (1985). Purification and properties of ornithine decarboxylase from Tetrahymena pyriformis. Biochimica et Biophysica Acta 831, 288-296.

SteVENS, L. \& Winther, M. D. (1979). Spermine, spermidine and 
putrescine in fungal development. Advances in Microbial Physiology 19, 63-148.

SteVvens, L., McKinnon, I. M. \& Winther, M. (1977). The effects of 1,4-diaminobutanone on polyamine synthesis in Aspergillus nidulans. FEBS Letters 75, 180-182.

TABOR, C. W. \& TABOR, H. (1984). Polyamines. Annual Review of Riochemistry 53, 749-790.

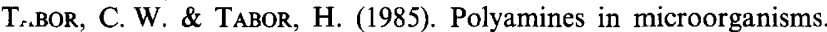
Microbiological Reviews 49, 81-99.

Tabor, C. W., Tabor, H., Tyagi, A. K. \& Cohn, M. S. (1982). The biochemistry, genetics and regulation of polyamine biosynthesis in Saccharomyces cerevisiae. Federation Proceedings 41, 3084-3088.

Von JAGOW, G. \& KLINGEnberG, M. (1970). Pathway of hydrogen in mitochondria of Saccharomyces carlsbergensis. European Journal of Biochemistry 12, 583-593.

Williams, J. L., Barnett, J. R., Ristow, J. L., Perrier, M. \& Davis, R. H. (1992). Ornithine decarboxylase gene of Neurospora crassa: isolation, sequence, and polyamine-mediated regulation of its mRNA. Molecular and Cellular Biology 12, 347-359.

WinTHER, M. \& STEVEnS, L. (1978). Polyamines stimulation of in vivo macromolecular synthesis in a putrescine auxotroph of Aspergillus nidulans. FEBS Letters 85, 229-232.

Zagon, I. S., Mclauglin, P. J., Seely, J. E., Hoeksma, G. W. \& Pegg, G. W. (1984). Autoradiographic localization of ornithine decarboxylase in mouse kidney by use of radiolabeled difluoromethylornithine. Cell and Tissue Research 235, 371-377. 